\title{
ON OBJECTIVE FUNCTION INTERPOLATION IN THE OPTIMIZATION OF ENGINEERING SYSTEMS
}

\author{
Institute of Technical Mechanics \\ of the National Academy of Sciences of Ukraine and the State Space Agency of Ukraine \\ 15 Leshko-Popel St., 49005,Dnipro,Ukraine; e-mail: yukv@i.ua; zinevich7385@gmail.com
}

This paper is concerned with preliminary estimation of the values of an objective function throughout its multidimensional domain of definition from a small number of points where its value is known. This problem arises at the stage of strategy selection for a further search for the objective function extremum in the optimization of various engineering systems. The aim of this paper is to construct an objective function interpolation technique for the case where the interpolation nodes are specified by an irregular set of points in a multidimensional cube. The main interpolation method is a sequential numerical solution of the Laplace equation and the diffusion equation on uniform meshes. The use of the diffusion equation in addition to the Laplace equation is justified in this paper by the need for interpolation quality improvement because otherwise the interpolating function develops unacceptably high gradients in the vicinity of interpolation nodes. It was shown that this undesirable phenomenon may be reduced considerably by determining the diffusion coefficient from the gradient of the interpolating function calculated by the Laplace equation. This made it possible to construct a technique for objective function interpolation in the optimization of engineering systems, which allows one to use an irregular set of points in a unit square as the interpolation nodes. The workability of the proposed technique was demonstrated for three essentially different test functions, and it was shown that the form of the initial function may be assessed for as few as three-four tens of interpolation nodes even though there are several minima in the domain of variables. The technique developed can be extended rather simply to the case of multiple variables where the interpolation nodes are specified in a unit cube. So this paper further develops existing approaches to the interpolation of multivariable functions in the most complex case where the interpolation node arrangement is irregular. The results obtained may be used in the optimization of engineering systems.

Keywords function interpolation, irregular set of points, multidimensional cube, Laplace equation, diffusion equation.

1. Kvasha Yu. A., Zinevych N. A. Aerodynamic optimization of spatial form of impeller blade of supersonic compressor stage (in Russian). Tekhnicheskaya Mekhanika. 2016. No. 3. Pp. 35-42.

2. Sobol I. M., Statnikov R. B. Optimal Parameter Selection in Multicriterion Problems (in Russian). Moscow: Nauka, 1981. 110 pp.

3. Chan-Sol Ahn, Kwang-Yong Kim. Aerodynamic design optimization of an axial flow compressor rotor. Proc. of ASME TURBO EXPO 2002. (Amsterdam, June 3-6, 2002). Amsterdam (The Netherlands), 2002. 7 p.

4. Sivashanmugam V. K., Arabnia M., Ghaly W. Aero-structural optimization of an axial turbine stage in threedimensional flow Proc. of ASME TURBO EXPO 2010. (Glasgow, June 14-18, 2010). Glasgow (UK), 2010. $14 \mathrm{p}$.

5. Finaev V. I. Design of Experiments and Experimental Data Processing (in Russian). Taganrog: Southern Federal University Publishers, 2013. 92 pp.

6. Response surface technology (in Russian). URL: http://www.iosotech.com/ru/response_surface.htm (last accessed on May 21, 2018)..

7. Press W. H. Laplace Interpolation. The University of Texas at Austin, CS 395T, Spring 2010. URL: http://numerical.recipes/CS395T/lectures2010/2010_19_LaplaceInterpolation.pdf. (last accessed: on May 20, 2018).

8. Caspers P. Laplace Interpolation. URL: https://quantlib.wordpress.com/tag/laplace-interpolation/ (last accessed: 20.05.2018).

9. Test functions for optimization (in Russian). Wikipedia. URL: https://ru.wikipedia.org/wiki/ естовые_функции_для_оптимиз ции (last accessed on May 20, 2018). 